\title{
海浜環境におけるステンレス鋼の発銹挙動 と耐銹性評価法*
}

\author{
武藤 泉**, 佐藤栄次 ${ }^{* *}$, 伊 藤 䧳** \\ ** 新日本製鐵株式会社鉄鋼研究所
}

\section{Rust Staining Resistance of Stainless Steels in a Marine Environment and Its Estimation Method*}

\author{
Izumi Muto**, Eiji Sato** and Satoshi Ito** \\ ** Steel Research Laboratories, Nippon Steel Corporation
}

\begin{abstract}
A new electrochemical evaluation method was presented to estimate the rating number of rust staining of stainless steels in a marine environment. In this accelerated test, rust staining resistance of stainless steels was evaluated from the time to pitting under the thin electrolyte layer that was generated by the capillary phenomenon through a cotton cloth. The incubation time to passive film breakdown under this thin electrolyte layer corresponds to initial atmospheric corrosion resistance. From the results of ten years exposure test, most of stainless steels experienced severe rust staining within the first two years exposure. All the types of stainless steel have the same tendency wherein rating number changes with the square of the inverse time. The rating number of stainless steels in the marine environment can be evaluated from this time dependence and the degree of initial rust staining. The latter can be estimated by newly developed test method.
\end{abstract}

Key words: stainless steels, atmospheric corrosion, rust staining, accelerated test, exposure test, electrochemical method, pitting, Weibull distribution

\section{1. 緒言}

ステンレス鋼は優れた耐食性と美しい表面状態を兼ね 備えた材料であることから，建築物の屋根や外装材とし て広く使用されている。しかし，海塩粒子量の多い環境 などでは，発銹などの大気腐食損傷が問題となる場合が ある(1)

このステンレス鋼の耐銹性を把握する手法としては， 大気暴露試験を実施することが確実であるが，結果を得 るまでに長い期間を必要とすること, 結果を定量的に評 価することが難しいなどの欠点がある。そこで，現在ま で各種の加速試験法が開発され，その適用方法について 多くの検討が加兄られてきた4) 15)。これらの試験法の多 くのものは, 特定の試験条件のもとでの発銹の程度か ら，鋼材の耐銹性を判定するものである。そのため，数

* 腐食防食'90 (東京) で発表

** 干 299-12 千葉県富津市新富 20-1 (20-1，Shintomi, Futtsu, Chiba-ken, 299-12 Japan)
種類のステンレス鋼の間での相対的な耐銹性は判定でき るが，実際に鋼種間にどの程度の耐銹性の差があるのか を定量的に評価することは困難である。さらに，このよ うな加速試験のデータから実環境で数年間使用した後の 発銹評点を推定することは不可能である。

本研究では，ステンレス鋼の耐銹性を定量評価でき， か岛革環境での発銹挙動を推定できる試験法を開発する ことを目的として以下の検討を行った。（1）実際の大気 環境での発銹挙動を把握するために，1～10 年間にわた り海浜環境に暴露されたステンレス鋼の発銹举動を解析 した。(2) それらの発銹挙動とステンレス鋼の水膜環境 下での耐局部腐食性との関係を利用して, 新しい試験法 を考案し，最後に（3）耐銹性の定量評価括よび実環境で の発銹状況予測手法について検討した。 


\section{2. 実験方法}

\section{1 大気暴露試験片の解析}

発銹状沇の解析に使用した試験片は, 1～10 年間 (1978 年〜1988 年) 兵庫県赤穂市の海岸で大気暴露したもので ある。Table 1 に, 大気暴露試験片の化学組成を示す。
試験片の大きさは，100 mm×150 mm であり，試験片の 表面仕上げは，2D 执よび2Bである。それ羿れ，2Dは 鋼材を冷間压延した後に焼鈍酸洗した子ので, 2B は 2D 仕上げ後に軽く冷間圧延を行ったものである。暴露地点 は海岸から約 $150 \mathrm{~m}$ で, JIS H 0521 のガーゼ法で計測

Table 1 Chemical compositions (mass \%) and surface finishes of stainless steels exposed to the marine environment.

\begin{tabular}{|c|c|c|c|c|c|c|c|c|c|c|c|}
\hline Specimen & $\begin{array}{l}\text { Yype or } \\
\text { Tradename }\end{array}$ & (Finish) & $\mathrm{C}$ & $\mathrm{Si}$ & Mn & $\mathrm{P}$ & $\mathbf{S}$ & $\mathrm{Cr}$ & $\mathrm{Ni}$ & Mo & Other \\
\hline $16 \mathrm{Cr}-9 \mathrm{Mn}-2 \mathrm{Ni}$ & YUS $120^{\mathrm{a}}$ & (2D) & 0.130 & 0.48 & 9.02 & 0.033 & 0.002 & 16.28 & 2.36 & & $\mathrm{Cu}: 1.00$ \\
\hline $18 \mathrm{Cr}-6 \mathrm{Ni}$ & YUS27A ${ }^{a}$ & $(2 \mathrm{~B})$ & 0.050 & 0.59 & 1.09 & 0.027 & 0.004 & 17.58 & 6.40 & & $\mathrm{Cu}: 1.85$ \\
\hline $17 \mathrm{Cr}-7 \mathrm{Ni}$ & 301 & (2B) & 0.100 & 0.58 & 1.20 & 0.027 & 0.005 & 17.49 & 7.57 & & \\
\hline $18 \mathrm{Cr}-8 \mathrm{Ni}$ & 304 & (2D) & 0.050 & 0.57 & 0.95 & 0.032 & 0.009 & 18.26 & 9.14 & & \\
\hline $18 \mathrm{Cr}-8 \mathrm{Ni}$ & 304 & $(2 \mathrm{~B})$ & 0.050 & 0.56 & 0.91 & 0.028 & 0.007 & 18.03 & 9.17 & & \\
\hline $17 \mathrm{Cr}-12 \mathrm{Ni}-2.5 \mathrm{MO}$ & 316 & (2B) & 0.060 & 0.51 & 1.02 & 0.031 & 0.006 & 17.00 & 12.60 & 2.21 & $\mathrm{Cu}: 0.30$ \\
\hline $18 \mathrm{Cr}-7 \mathrm{Ni}-2 \mathrm{Cu}-1 \mathrm{MO}$ & YUS $316 c^{a}$ & (2B) & 0.050 & 0.73 & 1.03 & 0.026 & 0.006 & 17.80 & 7.35 & 0.97 & $\mathrm{Cu}: 1.80$ \\
\hline $25 \mathrm{Cr}-13 \mathrm{Ni}-0.8 \mathrm{Mo}$ & YUS $170^{\mathrm{a}}$ & (2B) & 0.022 & 0.91 & 1.50 & 0.020 & 0.001 & 24.25 & 12.97 & 0.82 & $\mathrm{~N}: 0.345$ \\
\hline $10.9 \mathrm{Cr}$ & 409 & $(2 D)$ & 0.040 & 0.25 & 0.57 & 0.023 & 0.009 & 10.85 & & & $\mathrm{Ti}: 0.47$ \\
\hline $11 \mathrm{Cr}$ & YUS409D & $(2 \mathrm{~B})$ & 0.009 & 0.48 & 0.33 & 0.017 & 0.009 & 11.00 & & & $\mathrm{Ti}: 0.28$ \\
\hline $12 \mathrm{Cr}$ & YUS410 $\mathrm{W}^{\mathrm{a}}$ & $(2 B)$ & 0.017 & 0.48 & 0.47 & 0.021 & 0.005 & 12.10 & & & \\
\hline $13 \mathrm{Cr}$ & 410 & $(2 B)$ & 0.090 & 0.74 & 0.24 & 0.037 & 0.006 & 12.85 & & & \\
\hline $16.5 \mathrm{Cr}$ & YUS $430 D^{\mathrm{a}}$ & $(2 \mathrm{~B})$ & 0.007 & 0.13 & 0.78 & 0.025 & 0.006 & 16.53 & & & $\mathrm{Ti}: 0.35$ \\
\hline $17 \mathrm{Cr}$ & 430 & $(2 B)$ & 0.058 & 0.32 & 0.17 & 0.026 & 0.004 & 16.60 & & & \\
\hline $19 \mathrm{Cr}-2 \mathrm{Mo}$ & YUS190 ${ }^{\mathrm{a}}$ & (2B) & 0.005 & 0.06 & 0.12 & 0.034 & 0.007 & 19.00 & Mo: 1.78 & $\mathrm{Nb}: 0.2$ & $29 \mathrm{Ti}: 0$. \\
\hline
\end{tabular}

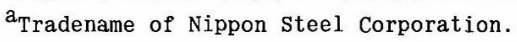

Table 2 Relationship between rating number and surface appearance of exposed specimens.

\begin{tabular}{|c|c|}
\hline Rating number & Appearance of surface \\
\hline 6 & No rust or no staining \\
\hline $5-3$ & $\begin{array}{l}\text { Increased degree of rust staining, separate and } \\
\text { small spots of rust }\end{array}$ \\
\hline $2-1$ & Discoloration and/or increased amount of rust \\
\hline 0 & Rust covering major part of surface \\
\hline
\end{tabular}

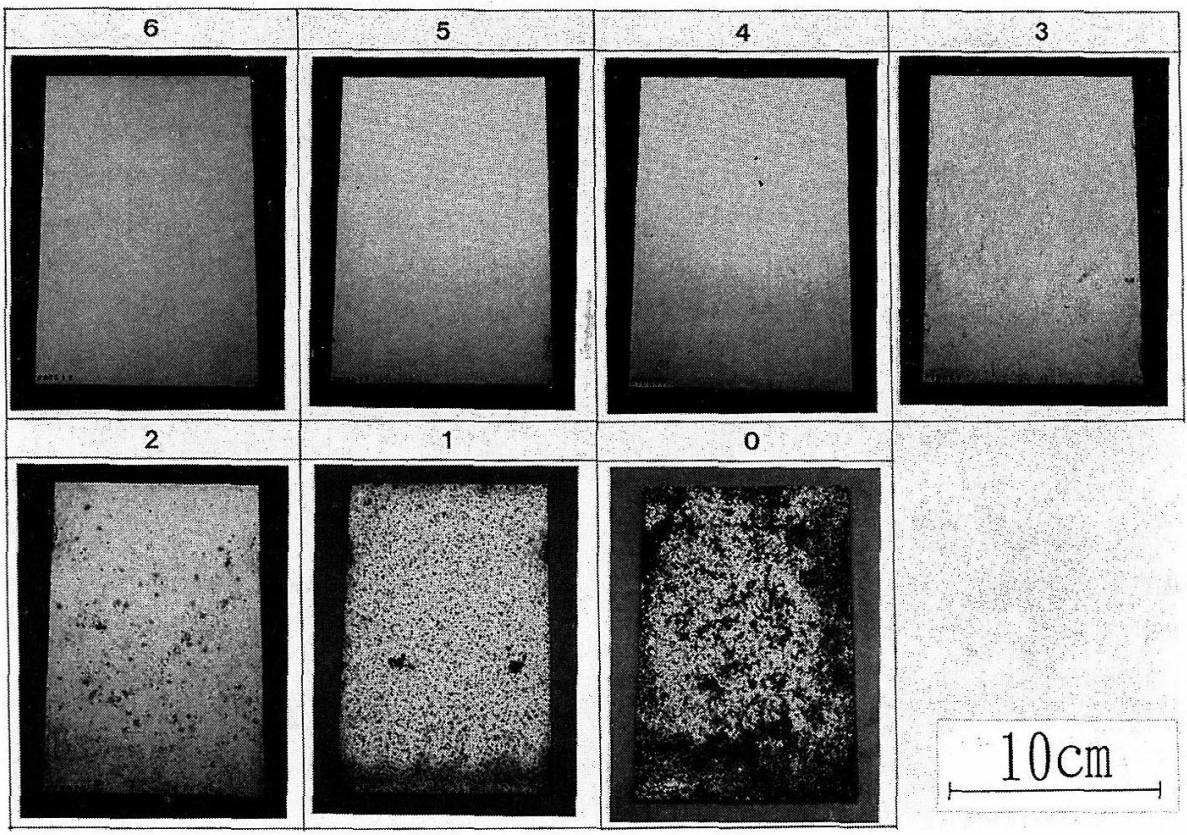

Fig. 1 Standard rating panels. 


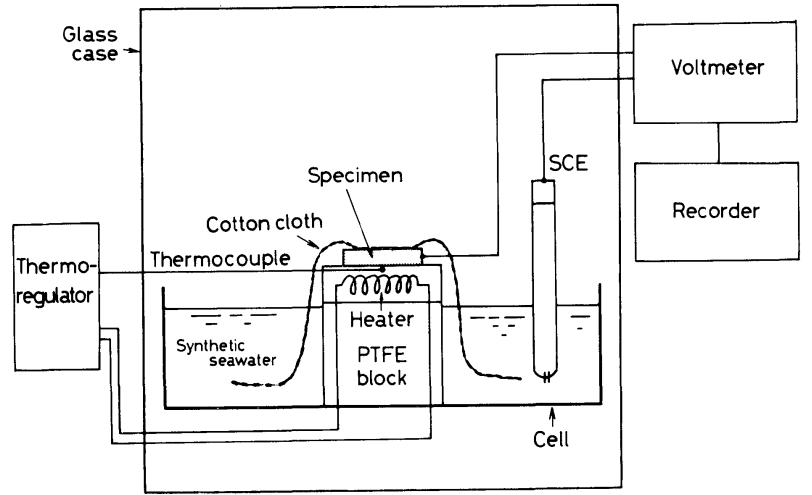

Fig. 2 Schematic illustration of new electrochemical evaluation method.

Table 3 Chemical compositions (mass\%) of stainless steels for the accelerated test.

\begin{tabular}{|c|c|c|c|c|c|c|c|c|c|c|c|}
\hline Specimen & $\begin{array}{l}\text { ype or } \\
\text { Tradename }\end{array}$ & (Finish) & $\mathrm{C}$ & Si & Mn & $P$ & $\mathbf{S}$ & $\mathrm{Cr}$ & $\mathrm{Ni}$ & Mo & other \\
\hline $1 \mathrm{Cr}$ & $\mathrm{Y}$ & ) & 3 & 40 & 5 & 18 & 02 & .74 & 0.06 & & \\
\hline 17 & 430 & & & 0 & & & & & 0.10 & & \\
\hline $19 \mathrm{Cr}-1 \mathrm{Mo}$ & - & (2B) & 0.012 & 0.31 & 0.14 & 0.031 & 0.001 & 19.28 & 0.29 & 0.98 & $\mathrm{Cu}: 0.37$ \\
\hline $19 \mathrm{Cr}-2 \mathrm{Mo}$ & YUS $190^{\mathrm{a}}$ & (2B) & 0.011 & 0.16 & 0.15 & 0.023 & 0.004 & 19.02 & Mo: 1.81 & $\mathrm{Nb}: 0.2$ & $29 \mathrm{Ti}: 0.18$ \\
\hline $18 \mathrm{Cr}-8 \mathrm{Ni}$ & 304 & (2B) & 0.069 & 0.48 & 0.89 & 0.027 & 0.003 & 18.29 & 8.74 & & \\
\hline $17 \mathrm{Cr}-12 \mathrm{Ni}$ & fo 316 & (2B) & 0.072 & 0.58 & 0.70 & & & 17. & 11.30 & 2.19 & 29 \\
\hline $25 \mathrm{Cr}-13 \mathrm{Ni}-0.8 \mathrm{Mo}$ & 10 YUS170 & (2B) & 0.019 & 0.93 & 0.43 & 0.034 & 0.001 & 24.68 & 12.78 & 0.73 & $N: 0.35$ \\
\hline
\end{tabular}

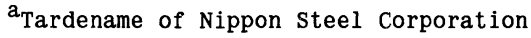

した平均海塩粒子量は $15 \mathrm{mg} \cdot \mathrm{m}^{-2} \cdot \mathrm{day}^{-1}$ であった。試 験片は，南向きで 30 度の傾斜をつけて暴露した。

発銹の評価は, Table 2 に示した基準に従い 0 から 6 の発銹評点により行った。また, 発銹評点の標準写真を

Fig. 1 に示した。

\section{2 耐銹性評価試験}

大気環境でのステンレス鋼の発銹は，（1）鋼材表面で の塩化物イオンなどを含む水滴の形成, (2) 水滴の乾燥 に伴う腐食性イオン種の濃縮と水膜が薄くなることによ る溶存酸素補給速度の増加, (3) 不動態皮膜破壊による 局部腐食発生と金属イオン溶出によるさび形成, といら 一連の過程を経るものと考えられる。したがって, 実環 境を模擬した液薄膜環境を実験室的につくり，そこでの 局部腐食発生までの時間を電気化学的に計測することに より，耐銹性を数值として定量的に評価できるものと考 えられる。

Fig. 2 に, 考案した耐銹性評価試験装置（加熱型液薄 膜電位法）の模式図を示す。これは, 著者の一人が以前 に開発した液薄膜電位法を加熱型に改良したものであ $ろ^{9)}$ 。試験片は両面テープでシートヒーターの上に固定 し, 試験液をしみ込ませたガーゼを試験片表面に密着さ せる。ガーゼの両端を液だめ内に浸すことにより, 試験 液は毛管現象により絶えず試験片表面に供給され薄い水
膜を形成する。さらに，試験片を加熱することで，試験 片表面の液膜を充分に薄くできるため，溶存酸素の補給 速度も速くなり, 同時に電解質の濃縮も起こり, 大気腐 食の起こる状況を模擬した条件となる。局部腐食発生ま での時間は, 試験片の電位変化から計測した。照合電極 には, 飽和カロメル電極 (SCE) を使用した。以下, 電位 の表示は $\mathrm{SCE}$ 基準とする。

Table 3 に, 促進評価試験に使用した試験片の化学組 成を示す。表面仕上げは，大気暴露材との対応関係を取 るために $2 \mathrm{~B}$ 仕上げとし, $20 \mathrm{~mm} \times 13 \mathrm{~mm}$ の面積を残し てシリコンラバー（信越化学製 KE41）で被覆した。ヒ 一ターの加熱温度は, $333 \mathrm{~K}\left(60^{\circ} \mathrm{C}\right)$ とし試験液には海浜 環境を想定して人工海水 (ASTM D-1141-52) を使用し た。

\section{3. 実験結果と考察}

\section{1 大気暴露試験片の発銹挙動}

Table 4 に, 大気暴露試験での各ステンレス鋼の暴露 年数ごとの発銹評点を示す。まず，ステンレス鋼の大気 暴露初期の耐銹性に及ぼす合金元素量の効果を把握する ために, 暴露期間 1 年の試験片について, 多重回帰分析 法により $\mathrm{Cr}, \mathrm{Ni}$ 和よび Mo 含有量と発銹評点との関係 式を求めた。Fig. 3 に, 得られた合金指標と発銹評点と 
Table 4 Rating number of specimens exposed to the marine environment.

\begin{tabular}{|c|c|c|c|c|c|c|c|}
\hline \multirow[t]{2}{*}{ Specimen } & \multirow{2}{*}{$\begin{array}{l}\text { Type or } \\
\text { Tradename }\end{array}$} & \multirow{2}{*}{ (Finish) } & \multicolumn{4}{|c|}{ Rating number } & \multirow[b]{2}{*}{ (year } \\
\hline & & & 1 & 2 & 4 & 10 & \\
\hline $16 \mathrm{Cr}-9 \mathrm{Mn}-2 \mathrm{Ni}$ & YUS $120^{\mathrm{a}}$ & (2D) & 5 & 2 & 1 & 1 & \\
\hline $18 \mathrm{Cr}-6 \mathrm{Ni}$ & YUS27A & (2B) & 5 & 2 & 2 & 1 & \\
\hline $17 \mathrm{Cr}-7 \mathrm{Ni}$ & 301 & (2B) & 5 & 2 & 2 & 1 & \\
\hline $18 \mathrm{Cr}-8 \mathrm{Ni}$ & 304 & (2D) & 5 & 2 & 2 & 1 & \\
\hline $18 \mathrm{Cr}-8 \mathrm{Ni}$ & 304 & (2B) & 4 & 2 & 2 & 1 & \\
\hline $17 \mathrm{Cr}-12 \mathrm{Ni}-2.5 \mathrm{Mo}$ & 316 & (2B) & 5 & 3 & 2 & 2 & \\
\hline $18 \mathrm{Cr}-7 \mathrm{Ni}-2 \mathrm{Cu}-1 \mathrm{Mo}$ & YUS $316 \mathrm{C}^{\mathrm{a}}$ & $(2 B)$ & 5 & 2 & 2 & 1 & \\
\hline $25 \mathrm{Cr}-13 \mathrm{Ni}-0.8 \mathrm{Mo}$ & YUS $170^{\mathrm{a}}$ & (2B) & 6 & 3 & 2 & 2 & \\
\hline $10.9 \mathrm{Cr}$ & 409 & (2D) & 2 & 0 & 0 & 0 & \\
\hline $11 \mathrm{Cr}$ & YUS $409 D^{a}$ & $(2 B)$ & 2 & 0 & 0 & 0 & \\
\hline $12 \mathrm{Cr}$ & YUS4 $10 w^{\mathrm{a}}$ & $(2 B)$ & 2 & 0 & 0 & 0 & \\
\hline $13 \mathrm{Cr}$ & 410 & (2B) & 3 & 1 & 0 & 0 & \\
\hline $16.5 \mathrm{Cr}$ & YUS430D & $(2 \mathrm{~B})$ & 4 & 2 & 2 & 1 & \\
\hline $17 \mathrm{Cr}$ & 430 & (2B) & 4 & 1 & 0 & 0 & \\
\hline $19 \mathrm{Cr}-2 \mathrm{Mo}$ & YUS $190^{\mathrm{a}}$ & (2B) & 6 & 3 & 2 & 2 & \\
\hline
\end{tabular}

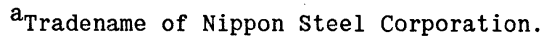

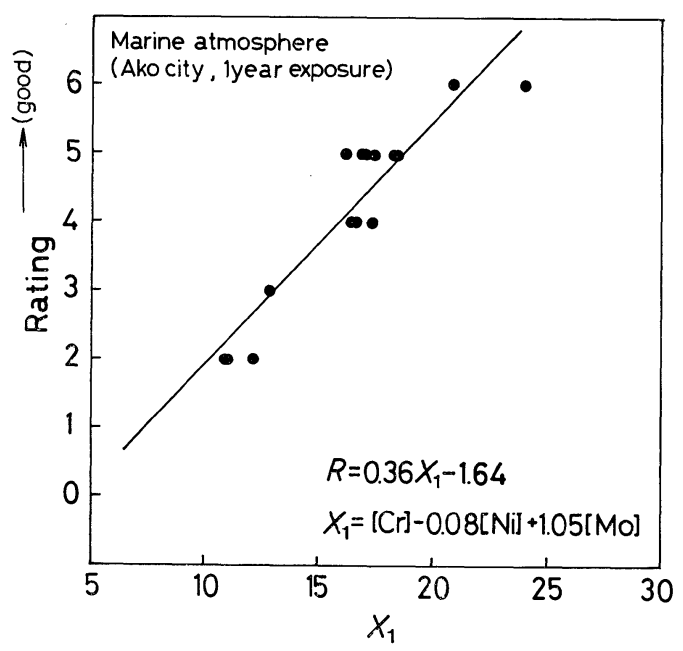

Fig. 3 Effect of alloy compositions on the rating number after 1 year in the marine environment.

の関係を示す。合金元素量と発銹評点との関係は, 次式 で表せることがわかった。

$$
R_{1}=0.36 X_{1}-1.64
$$

ただし

$$
\begin{aligned}
& R_{1}: 1 \text { 年後の発銹評点 } \\
& X_{1}=[\mathrm{Cr}]-0.08[\mathrm{Ni}]+1.05[\mathrm{Mo}] \approx[\mathrm{Cr}]+[\mathrm{Mo}] \\
& X_{1}: \text { 而銹性合金指標 }
\end{aligned}
$$

$[\mathrm{Cr}],[\mathrm{Ni}],[\mathrm{Mo}]: \mathrm{Cr}, \mathrm{Ni}, \mathrm{M}_{0}$ 含有量 (mass\%) ここで, 耐銹性合金指標 $X_{1}$ の中の各係数は, 耐銹性 飞寄与する各合金元素の度合いを示しているものと考光 られる。Ni の係数が 0 に近いことから，Ni の初期発銹 に対する効果は，耐孔食性などと同じく，極めて小さい ものと推察され ${ }^{18) \sim 18)}$, 耐銹性合金指標快実質的に $[\mathrm{Cr}]+$

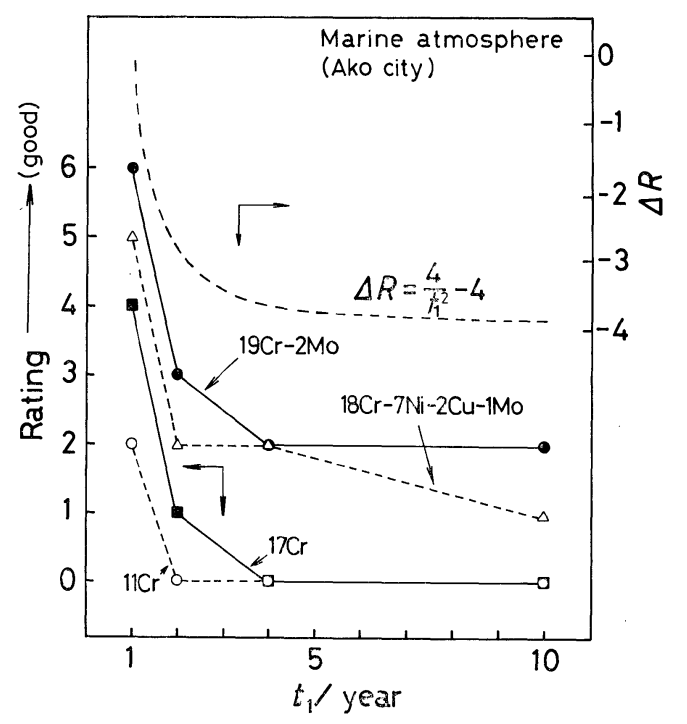

Fig. 4 Change in the rating number of different types of stainless steels in the marine environment.

[Mo］と表せるものと考光られる。また，N は耐局部腐 食性にとって有効な元素であるが18)，その効果を合金指 標として定量的に把握することは，本研究ではできなか った。

次に, 大気暴露材の 1 年以降の発銹状態の劣化挙動を 調べた。Fig. 4 亿, 合金元素量の異なる 4 種類のステン レス鋼の発銹評点の経時変化を示す。また, Fig. 5 には, 暴露年数の逆数の 2 乗に対する発銹評点の変化を示す。 このような整理をするといずれのステンレス鋼の場合に も, 発銹評点と年数との間に直線関係が成り立つことが わかった。したがって, 1 年目と $t_{1}$ 年目の発銹評点の值 の違い $\Delta R$ は, 次式のように表せる。 


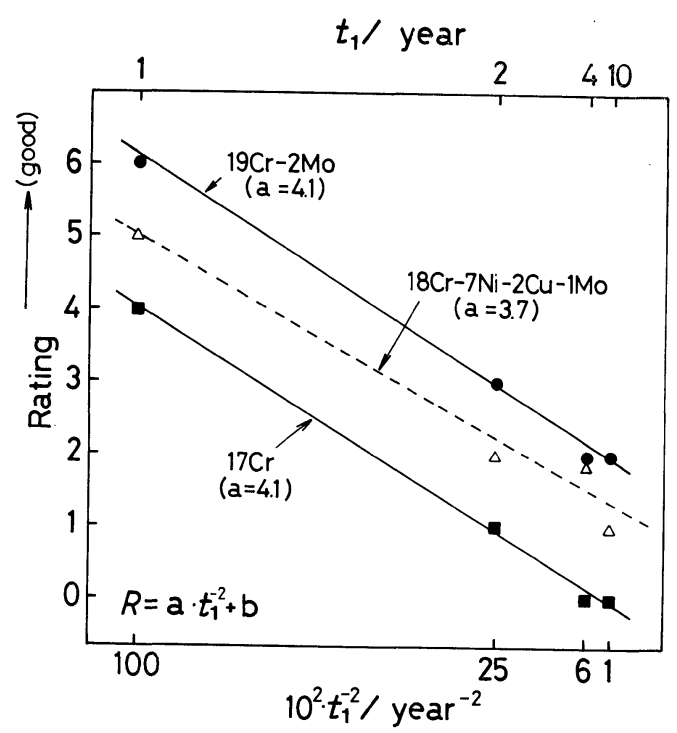

Fig. 5 The dependence of the rating number on square of the inverse time.

$$
\Delta R=4\left(t_{1}^{-2}-1\right)
$$

ここで, (1) 式と (2) 式とから, $t_{1}$ 年後の発銹評点 $R$ は，次式のように表せることになる。

$$
\begin{aligned}
R= & R_{1}+\Delta R \\
& =\left(0.36 X_{1}-1.64\right)+\left(4 t_{1}^{-2}-4\right)
\end{aligned}
$$

このように, ステンレス鋼の発銹劣化挙動は, 合金元素 量に依存する初期発銹の部分 $R_{1}$ とその後の劣化の部分 $\Delta R$ とに分けて整理できるものと思われる。このように, ステンレス鋼の発銹評点変化を鋼種に依存する 1 年目と それ以降の時間に依存する項とに分けて表すことができ たのは, 海浜環境での発銹が 1 年程度で安定状態に近づ くためではないかと考えられる19)。ここで，(3) 式にお いて鋼種に依存する初期発銹の程度を実験室促進試験か ら求めることができれば，(3) 式を利用して $t_{1}$ 年後の発 銹評点を推定できることになる。ステンレス鋼の耐銹性
は， $\mathrm{N} や \mathrm{Cu}$ など今回合金指標として把握できなかった 元素や表面仕上げなどの影響を受けることから, 次に加 速試験法により初期発銹の程度を推定する方法について 検討した。

\section{2 加熱型液薄膜電位法による耐銹性評価}

Fig. 6 K, 加熱型液薄膜電位法での試験片の自然電極 電位の経時変化を示す。いずれの鋼種の昜合も, はじめ $0 \mathrm{~V}$ 付近にあるが数回の振動の後に $-0.4 \mathrm{~V}$ 付近に急激 に移行したまま復帰しなくなる。このとき, 試験片表面 に成長性の局部腐食が発生したものと考えられる。実 際, 自然電位が $-0.4 \mathrm{~V}$ 付近に変化した後の試験片表面 には, 孔食状の局部腐食が発生していることが確認され た。そこで, 試験開始からこの自然電極電位が卑に移行 するまでの時間を液薄膜環境での局部腐食発生時間とし て，耐銹性定量化のためのパラメータとした。

このような局部腐食発生現象は確率過程としてとらえ られるため ${ }^{20)}$, 鋼種間での耐銹性を定量的に比較する場 合には，測定值を統計処理することが有効である。本法 での局部腐食発生時間は，不動態皮膜が破壊されるまで の時間であると考えることがでさるので, 応力腐食割れ の破断時間などと同じく最弱リングモデルから導かれる ワイブル分布で整理できると考えられる ${ }^{21)}$ 。Fig. 7 に, 局部腐食発生時間をワイブルプロットした結果を示す。 いずれのステンレス鋼の結果も直線で整理できることか ら, 本法での局部腐食発生時間はワイブル分布に従らも のと考えられる。また，Fig. 7 に示したように，同一鋼 種でも局部腐食発生までの時間には，大きなばらつきが あるため, 鋼種間での耐銹性を定量的に比較するために は, 統計処理が不可欠と考えられる。Table 5 に, 加熱 型液薄膜電位法で得られた各鋼種の局部腐食発生時間の ワイブル分布のパラメータを示す。直線の傾きに相当す る形状パラメータ ( $m$ 值) は, 分布形状を表して扣り, 本 研究では 2.1〜 4.3 の範囲であり, 各ステンレス鋼の局部 腐食発生までの時間分布形状は，ほぼ同一であると考光

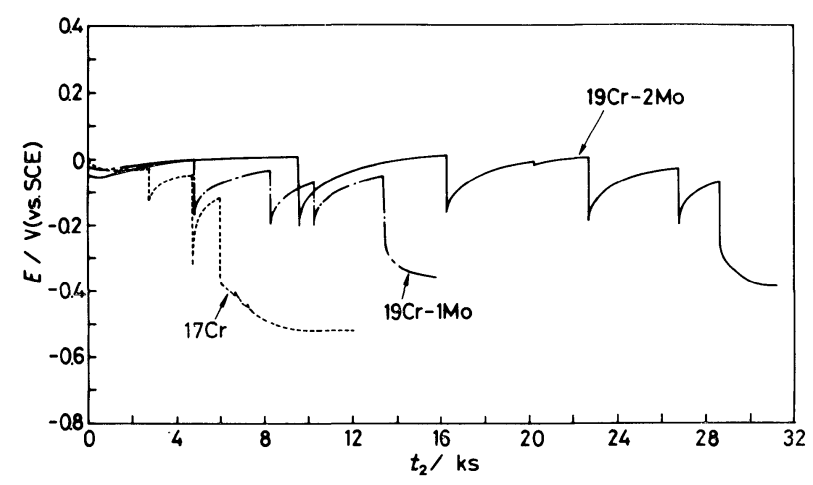

Fig. 6 Potential-time curves for stainless steels obtained by new electrochemical evaluation method. 
Table 5 Parameters of Weibull distributions of the incubation time to pit initiation for stainless steels.

\begin{tabular}{lcc}
\hline Specimen & Shape parameter, m & Mean value, $\mu(\mathrm{ks})$ \\
\hline $11 \mathrm{Cr}$ & 4.3 & 4.50 \\
$17 \mathrm{Cr}$ & 2.2 & 6.78 \\
$19 \mathrm{Cr}-1 \mathrm{Mo}$ & 2.2 & 13.80 \\
$19 \mathrm{Cr}-2 \mathrm{Mo}$ & 2.2 & 16.26 \\
$18 \mathrm{Cr}-8 \mathrm{Ni}$ & 3.6 & 4.92 \\
$17 \mathrm{Cr}-12 \mathrm{Ni}-2.5 \mathrm{Mo}$ & 2.1 & 9.72 \\
$25 \mathrm{Cr}-13 \mathrm{Ni}-0.8 \mathrm{Mo}$ & 2.5 & 24.12 \\
\hline
\end{tabular}

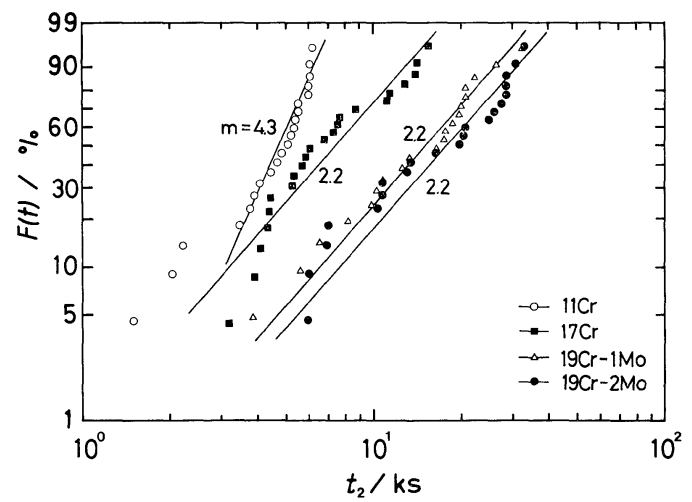

Fig. 7 Weibull distributions of the incubation time to pit initiation.

られる。そこで, 分布の平均值で, 相対的な耐銹性を比 較することにした。ここで，加速試験法の試験片面積は $2.6 \mathrm{~cm}^{2}$, 大気暴露試験片の大きさは $150 \mathrm{~cm}^{2}$ と異なる。 このため, 本法での局部腐食発生までの時間を単純に暴 露試験片での局部腐食発生までの時間と結び付けて考学 ることはできない。しかし，仮に鋼種間の耐銹性を時間 分布の下限值で比較したとしたら，暴露試験片内に执い ては, 試験片内に最初に孔食が発生するまでの時間で比 較していることに対応するものと考えられる。しかし， 今回のよらに時間分布の平均值で比較するといらこと は, 平均値は分布下限值よりも長時間側に位置している ため, 暴露試験片内にある程度の個数の孔食が発生する までの時間で耐銹性を比較することに対応することにな るものと考学られる。平均值を利用することで，より現 実に即した状態で耐銹性の比較ができるものと推察され る。

次に, 上記の手順によって求めた局部腐食発生時間の 平均値 $\mu$ とステンレス 鋼の合金元素量との関係を多重 回帰分析法により求めた結果を Fig. 8 に示す。図に示し たように，局部腐食発生時間の平均値 $\mu$ 之合金元素量と の関係は，次式で表せることがわかった。

$$
\mu(\mathrm{ks})=1.58 X_{2}-16.70
$$

ただし

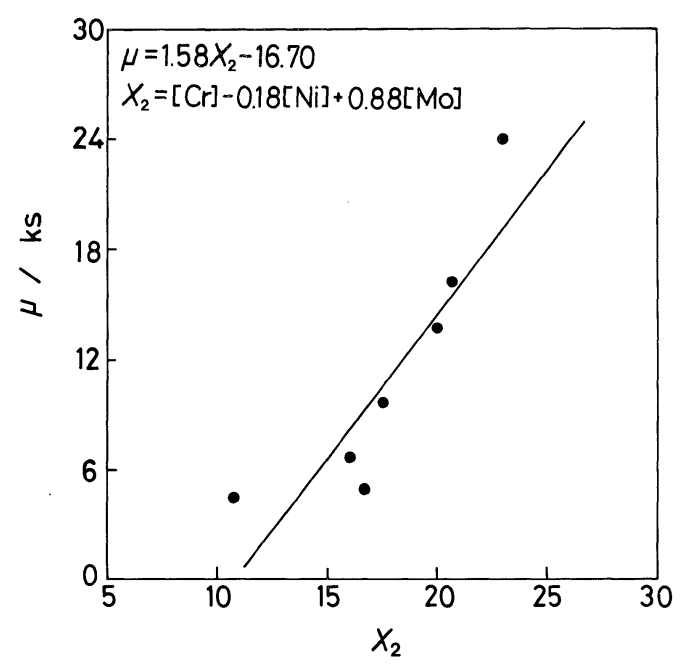

Fig. 8 Effect of alloy compositions on the mean value of the incubation time to pitting $(\mu)$ by the accelerated test.

$X_{2}=[\mathrm{Cr}]-0.18[\mathrm{Ni}]+0.88[\mathrm{Mo}] \approx[\mathrm{Cr}]+[\mathrm{Mo}]$

$X_{2}$ ：液薄膜環境での耐食性合金指標

ここで，この合金指標は $[\mathrm{Cr}]+[\mathrm{Mo}]$ と表せるものと考 えられる。このよらに, 液薄膜環境での耐食性を示す合 金指標は, 先に示した大気暴露材の解析から求めた (1) 式の耐銹性合金指標とほぼ一致する。すなわち, $\mathrm{Cr}$ と Mo の酎銹性改善効果が同程度で, Ni は耐銹性にとっ て効果がない, という 2 点が先に示した大気暴露初期の 耐銹性と同じく，液薄膜環境での局部腐食発生時間につ いても認められたことになる。ステンレス鋼での合金元 素の添加効果が, 実環境と液薄膜環境で同じになったこ とから, 今回考案した加熱型液薄膜電位法は, 海浜環境 での初期発銹（1 年間暴露）に対する耐食性を適切に加 速評価しているものと考えられる。

\section{3 加熱型液薄膜電位法による発銹寿命予測}

上述した結果によって, 加熱型液薄膜電位法での局部 腐食発生時間の平均值 $\mu$ の合金元素量依存性 $X_{2}$ と, 海. 浜環境暴露試験に招ける初期耐銹性を表す耐銹性合金指 標 $X_{1}$ とが等しいことがわかった。 


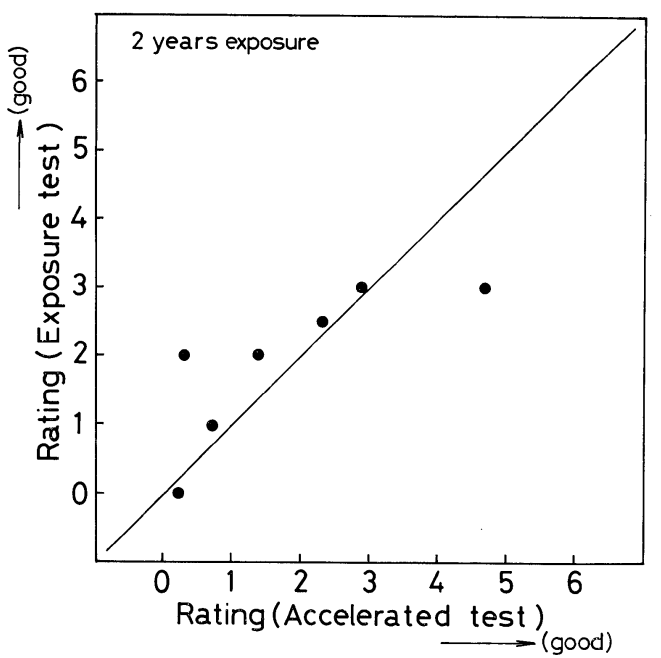

Fig. 9 Relationship between the rating number of specimens exposed to the marine environment and that estimated from the accelerated test.

$$
X_{1}=X_{2}
$$

そこで, この関係を利用して加熱型液薄膜電位法により ステンレス鋼の初期発銹の程度および $t_{1}$ 年後の発銹状 況を推定する手法について検討を加えることにする。

液薄膜環境での耐銹性合金指標 $X_{2}$ と加熱型液薄膜環 境での局部腐食発生時間 $\mu$ との関係を表している (4) 式を整理し（5）式を代入すると, 実環境での初期発銹に 対する耐銹性合金指標 $X_{1}$ と $\mu$ と関係を得ることがで きる。

$$
X_{1}=\mu / 1.58+10.6
$$

そして，この（6）式を（3）式を代入することで, 加 熱型液薄膜電位法の $\mu$ 值と $t_{1}$ 年後のステンレス鋼の発 銹評点 $R$ との関係式が得られる。

$$
R=(\mu / 4.39+2.18)+\left(4 t_{1}{ }^{-2}-4\right)
$$

Fig. 9 に, Table 4 に示した各鋼種の $\mu$ 值を使用し て（7）式から推定した 2 年後の発銹評点と 2 年間の大 気暴露試験材の発銹評点との関係を示す。両者の対応関 係は比較的良好であることから，(7) 式を用いて加熱型 液薄膜電位法による $\mu$ 值から海浜環境でのステンレス 鋼の発銹挙動を推定でさるものと考えられる。

また, 大気暴露材の解析結果から得られた耐銹性合金 指標 $[\mathrm{Cr}]+[\mathrm{Mo}]$ から, 直接（3）式を利用して数年後の 発銹評点を推定する方法に比べ, 加熱型液薄膜電位法を 用いる方法では表面状態や介在物などの試験片固有の要 因をも含めて発銹評点を推定できるものと考光られる。

\section{4. 結 論}

（1）海浜環境で 1 10 年間大気暴露したステンレ ス鋼の発銹挙動の解析から, $t_{1}$ 年後の発銹評点 $R$ は,

$$
\begin{aligned}
& R=\left(0.36 X_{1}-1.64\right)+\left(4 t_{1}{ }^{-2}-4\right) \\
& X_{1} \text { : 而銹性合金指標 }(=[\mathrm{Cr}]+[\mathrm{Mo}])
\end{aligned}
$$

と表せることがわかった。

（2）ステンレス鋼の耐銹性を定量評価でき，かつ数 年後の発銹評点を予測できる耐銹性評価試験法（加熱型 液溥膜電位法）を新しく提案した。

（3）加熱型液薄膜電位法での局部腐食発生時間の平 均值を $\mu(\mathrm{ks})$ とすると, $t_{1}$ 年後の発銹評点 $R$ は次式で 与えられることを明らかにした。

$$
R=(\mu / 4.39+2.18)+\left(4 t_{1}{ }^{-2}-4\right)
$$

(Received July 16, 1992)

\section{文献}

1）根本力男，藤原最仁，金子 智，栗本昭仁，小林 未子夫, 木谷 滋：腐食防食 '85, p. 131 (1985).

2) 中田潮雄, 稲垣博已, 林 義信, 若曾根 肇, 橋 本 潔, 福来光男, 細羽満男, 柿島孝男: 第35回 腐食防食討論会予稿集, p. 183 (1988).

3）吉井紹泰, 西川光昭, 林 公隬, 川野敏範, 福来 光男, 細羽満男, 柿島孝男: 第36回腐食防食討論 会予稿集, p. 221 (1989).

4) J.F. Bates \& E. H. Phelps: ASTM STP 369, p. 200 (1963).

5) G. F. Bush, W. J. Garwood \& B. E. Tiffany: ASTM STP 369, p. 209 (1963).

6) 浅田千秋, 野崎善蔵, 椙山太郎, 稲垣修一：防食 技術，15, 160 (1966).

7) 中田潮雄, 伊藤 功, 小野山征生, 稲垣博己：鉄 之鋼，67，S 1231 (1981).

8）遅沢浩一郎, 根本力男, 藤原最仁：腐食防食協会 '82 年春期学術講演大会予稿集, p. 189 (1982).

9) 伊藤 跧, 藪本政男, 小俣裕保, 村田朋美：第29 回腐食防食討論会予稿集 p. 178 (1982); 伊藤 㩚, 藪本政男, 村田朋美：鉄之鋼，68，S1484 (1982); S. Ito, M. Yabumoto, H. Omata, \& T. Murata: "Passivity of Metals and Semiconductors," Ed. by M. Froment, p. 637, Elsevier Science Publishers B.V. (1983).

10）伊東健次郎, 吉井紹泰：鉄と鋼， 72, S 1436 (1986).

11）小林未子夫，木谷 滋，根本力男，藤原最仁，金 子 智, 栗本昭仁: 腐食防食 '85, p. 135 (1985).

12）金子 智, 栗本昭仁, 小林未子夫，木谷 滋，根 本力男, 藤原最仁: 腐食防食 '85, p. 139 (1985).

13）大串徹太郎：防食技術, 34, 437 (1985).

14）吉井紹泰, 伊東健次郎, 野上 誠：日新製鋼技報, 59, 1 (1988).

15）木谷 滋：防錆管理，32，375 (1988); 木谷 滋, 御所窪賢一：腐食防食 '89, p. 203 (1989).

16) M. O. Speidel: Proceedings of International Conference on Stainless Steels, p. 25, ISIJ 
(1991).

17）小泉重信, 樫野紀元, 本橋健司, 富坂 崇, 金子 智：日本建築学会大会学術講演概要集, p. 829 (1988).

18) J. R. Kearns \& L. R. Barkowski: Mater. Per- form., 27 [2] 47 (1988).

19) A. Karlsson \& J. Olsson: Proc. 7th Scand. Corros. Cong., p. 71 (1975).

20) T. Shibata: ISIJ International, 31, 115 (1991).

21）柴田俊夫, 竹山太郎：防食技術, 30, 47 (1981). 